\title{
A Conceptual Study of Metaphors in Moroccan Tachelhit Variety
}

\author{
Youness Boussaid \\ Center of Letters and Human Sciences \\ Ibn Zohr University \\ Agadir, Morocco
}

\begin{abstract}
This paper investigates conceptual metaphors in the Moroccan Tachelhit variety in the light of the contemporary theory of metaphor advanced by Lakoff and Johnson (1980). The main objective of this research is to find out the conceptual differences between Tachelhit and English language. It also aims at contributing to the field of metaphor in Tamazight linguistics as well as filling the gap that exists in the literature. This qualitative research adopted content analysis as a technique with which data is collected, categorized, and analyzed. This research shows that metaphor can be used as a tool to examine the cultural groupthink of communities. The main findings of the present study include the conceptual differences between Tachelhit and English in metaphors such as: TIME IS A HUMAN BEING, NEWS IS A HUMAN BEING, DIRECTNESS IS UP, WORDS ARE LIQUID, HUNGER IS A KILLING THING, WEAKNESS IS EMPTINESS, GOODNESS IS A STRAIGHT LINE, MONEY IS DIRT, USEFULNESS IS A PRECIOUS OBJECT and REPUTE IS A DELICATE OBJECT; which are all examples of conceptual metaphors that exist in Tachelhit. This research paper also demonstrates that metaphor can structure gestures the way it structures metaphoric linguistic expressions. Conceptual metaphors are vital elements that need be taken into consideration in intercultural as well as intracultural contexts to overcome communication failures.
\end{abstract}

Keywords : conceptual metaphor theory, gesture, Tamazight, Moroccan Tachelhit

Cite as: Boussaid, Y. (2020). A Conceptual Study of Metaphors in Moroccan Tachelhit Variety. Arab World English Journal for Translation \& Literary Studies 4 (2) 31-55.

DOI: http://dx.doi.org/10.24093/awejtls/vol4no2.3 


\section{Introduction}

Metaphor has been a study focus since and before the times of Plato and Aristotle. Since then, metaphor was considered a mere linguistic ornament that is used only in poetry, and far away from being unique to everyday language. With advancements in cognitive linguistics, especially with the Contemporary Theory of Metaphor (1992) by George Lakoff and Mark Johnson, a myriad of research followed the trail to study metaphor as a matter of, not only language but cognition as well. This article follows the footpath of the contemporary theory of metaphor in that it considers metaphor as a "linguistic, conceptual, socio-cultural, neural, bodily phenomenon" (Kövecses, 2005, p.8).

There is a multitude of studies researching conceptual metaphors in different languages. However, no research has yet been done to study conceptual metaphors in Tachelhit. Tachelhit is a dialect of Tamazight ${ }^{1}$ or Berber language. Tamazight is a language within Afro-asiatic family and is spoken in the so-called Tamazgha region. This region includes North Africa, the Sahara, and West African Sahel (Chaker \& Mettouchi, 2006).

As stated by Chaker and Mettouchi (2006) in the Concise Encyclopedia of Languages of the World, about $40 \%$ of the Moroccan population are Amazigh. In Morocco, there are three dialects within the Tamazight language. Tarifit is spoken in the north, Tamazight ${ }^{2}$ in the center, Tachelhit, which is the concern of this study, is spoken in the South of Morocco (Chaker \& Mettouchi, 2006).

This piece of research is of paramount importance in that, first of all, it contributes to Tamazight linguistics which shows the paucity of research in the field of cognitive linguistics. This research also contributes to the academic study of Tachelhit metaphor in light of the contemporary theory of metaphor by Lakoff and Johnson (1980), which is virtually nonexistent. Secondly, this research article also seeks to examine the universality of metaphors. It does so by testing the hypothesis which postulates that some metaphors are universal. Studying metaphors in Tachelhit will shed light on the cultural models ${ }^{3}$ that characterize some of the conceptual metaphors in Tachelhit as well as reveal the extent to which these metaphors are universal. Last but not least, the significance of this study is attested and witnessed in its attempt to overcome intercultural communication barriers and failures caused by unawareness of metaphor variation across languages.

Unlike the theory of metaphor in Metaphors We Live By by Lakoff and Johnson (1980), this article attends more to metaphorical variation and causes of these variations among cultures. It does so by examining metaphors in Tachelhit language in comparison with the English language. This study also focuses on metaphoricity in gesture in the context of Amazigh culture. The objective of this research can be rendered into the following question which this study will try to answer: Are there any conceptual metaphors which are different between Tachelhit and English? 


\section{Literature Review}

Metaphor is from the Greek word metaphorá which means transference. On the word of Bussmann (1996), 'metaphor' stands for a figure of speech in ancient rhetoric from which it was taken. According to Lakoff (1992), the word metaphor "was defined as a novel or poetic expression where one or more words for a concept are used outside of its normal conventional meaning to express a similar concept" (p.202). With the contemporary theory of metaphor advanced by Lakoff and Johnson (1980), metaphor is not regarded to any further extent as a matter of language only, but of thought as well.

Metaphor has been a subject of academic and intellectual discussion since and before the times of Plato and Aristotle. Furthermore, conceptual metaphor was a subject of deliberation for many other philosophers such as Locke and Kant (Kövecses, 2010). What is new in the contemporary theory of metaphor, as mentioned in Metaphor by Kövecses (2010), is that it is "a comprehensive, generalized, and empirically tested theory" (p. xii).

Micheal Reddy is to be considered the first to usher in, in his influential book The Conduit Metaphor (1979), the contemporary theory of metaphor which stipulates that the conventional everyday language is conceptual in nature (Lakoff, 1992). The traditional assumption regards everyday language as literal and non-metaphorical. This erroneous assumption is refuted in Metaphors We Live By by Lakoff and Johnson (1980) who view everyday language as a matter of cognition. Lakoff and Johnson go further to assert that conceptual metaphors that characterize everyday language define our everyday realities and activities in that they structure what we perceive and how we function.

As stated by Lakoff and Johnson (1980), "the essence of metaphor is understanding and experiencing one kind of thing in terms of another (p.5)." Metaphor, according to them, is of three types: structural metaphors, orientational metaphors, and ontological metaphors. According to Lakoff and Johnson, structural metaphors are those metaphors that structure a concept in terms of another. The source provides rich resource by which to understand the target. For example, the concept argument is experienced and understood in terms of another concept war as will be shown below. The following are exemplary structural metaphors taken from Lakoff and Johnson (1980):

\section{ARGUMENT IS WAR ${ }^{4}$}

Your claims are indefensible.

I demolished his argument.

He shot down all of my arguments (p. 4).

\section{IDEAS ARE FOOD}

Half-baked ideas.

I just can't swallow that claim.

There are too many facts here for me to digest them all (p. 46).

\section{THORIES ARE BUILDINGS}

The theory needs more support.

Arab World English Journal for Translation \& Literary Studies 
We need to buttress the theory with solid arguments.

They exploded his latest theory (p. 46).

\section{TIME IS MONEY}

You're wasting my time.

I don't have time to give you.

How do you spend your time these days?

He's living on borrowed time (pp. 7-8).

The second type of metaphor is the orientational one. In Metaphors We Live By (1980), orientational metaphors "organize a whole system of concepts with respect to one another" (p.14), using spatial orientations such as up, down, in, and out. The following conceptual metaphors are orientational (Lakoff \& Johnson, 1980):

\section{HAPPY IS UP, SAD IS DOWN ${ }^{5}$}

I'm feeling up

That boosted my spirits

My spirits rose

I'm feeling down

He's really low these days (p. 15).

Other conceptual metaphors fall within the category of ontological metaphors ${ }^{6}$. Ontological metaphors, on the other hand, do not structure one concept in terms of another. However, they "enable speakers to conceive of their experiences in terms of objects, substance, or container" (Kövecses, 2010, p.328). For example, in the first sentence: My fear of insects is driving my wife crazy, the fear here, which is a feeling, is conceived of as on object that frightens the wife. The following are other ontological metaphor examples taken from Lakoff and Johnson (1980):

My fear of insects is driving my wife crazy (p.26).

I can't keep up with the pace of modern life (p.27).

My mind just isn't operating today (p.27)/ his mind snapped (p.28).

Her ego is very fragile (p. 28).

As mentioned earlier, the contemporary theory of metaphor considers metaphor not purely as a linguistic phenomenon, but also a neural experience. This neural experience of metaphor is known as the neural theory of metaphor. According to this neural theory (Lakoff, 2004-2008), certain neurons in the brain are activated or "fired" when other neurons corresponding to certain concepts or actions are activated. These neural connections are made through the everyday embodied experience. For example, the conceptual metaphor AFFECTION IS WARMTH activates two areas in the brain corresponding, respectively, to affection and warmth. These two concepts are connected or "wired" together because of the embodied experiences. One example of this 
embodied experience is the child who can feel motherly affection through being close to feeling body warmth of his mother (Kövecses, 2005).

Kövecses (2010) claims that universality of some metaphors "arises from the universal aspects of the human body" (p.197) as seen with the AFFECTION IS WARMTH conceptual metaphor. However, the universal aspects of the human body do not necessarily lead to universal metaphors. Languages can share many conceptual metaphors, but at the same time can differ on others. For example, languages can differ in the metaphors that involve "heart". In Zulu, the heart is associated with "anger and patience-impatience, tolerance-intolerance (Kövecses 2010, p.69)" whereas, in English, the heart is associated with love and affection.

According to Kövecses (2010), there are two causes of cross-cultural variation in metaphor. The first is the broader cultural context. This refers to the "governing principles and key concepts in a given culture (p.218)." For example, in Euro-American culture, anger is conceptually originated from the four humors (phlegm, black bile, yellow bile, and blood). It is also believed that the four humors determine the type of body, personality, and medical problems. Another example of broader cultural context comes from Chinese culture. In Chinese culture, the concept of anger $n u$ is closely related to the concept of $q i$ which means energy. Therefore, it is believed that for a person to be calm and in harmony, $q i$ must be in balance. The concept of anger in EuroAmerican and Chinese cultures is explained in terms of the four humors and qi, respectively (Kövecses, 2010).

The second cause, according to Kövecses (2010), is the natural and physical environment of a culture. The environment at which a given language is located shapes and influences that language in many ways. This impact can be seen in the metaphorical linguistic expressions that speakers from different habitats use to perceive of their 'universes.' For example, speakers of Arabic may be acclimatized to perceiving camels as ships of deserts. Another example of the habitat being a cause of metaphorical variation, mentioned in Teaching and Learning English Metaphors by Krishnamurthy (2005), is the metaphoric use of ети to refer to a fast person in Australian English.

Metaphor, apart from being a social-cultural phenomenon, as seen above, is correspondingly bodily in the sense that it affects and structures gestures the way it structures linguistic expressions (Cienki, 2008; McNeil, 1992). McNeil (1992) considers gestures and language to be "truly integral parts of a single process, with the gestures manifesting the imagery that is inherent in this process at an early stage" (p.105). Gestures, or gesticulants, according to McNeil, are regarded as symbols that display "imagery of what the speaker is thinking about." Since most speakers oblivious about their gestures, meticulous observers can make use of gestures of the speakers to tell what they intend to say or even "read" their minds. ${ }^{7}$ Metaphoric gestures can be seen when people talk about the past and future. When speaking about the past, people put their hands near the back of their shoulders or heads to refer to the past; while they put their hands forward to refer to the future. ${ }^{8}$ The conceptual metaphors that structures gestures in this context are: PAST IS BACKWARD, FUTURE IS FORWARD. These metaphorical gestures can also be called "deictic gesticulants" (McNeil, 1992) since they refer to temporal locations, past and future.

Arab World English Journal for Translation \& Literary Studies 
Further examples of conceptual metaphors and their gestural manifestations will be discussed below.

McNeil (2005) also demonstrates that metaphoric gestures can be expected or unexpected. Expected metaphoric gestures are those that comply with the cultural models, while the many unexpected ones are proved to be metaphoric only if their purpose is considered in relation to the discourse context.

Metaphors are not just a matter of language, but of thought as well. Thibodea and Boroditsky (2011) argue that the use of metaphor exerts a strong influence on the way we reason about complex problems. For example, the use of metaphorical frames can create huge differences in opinion between Democrats and Republicans (Thibodeau \& Boroditsky, 2011; Lakoff, 2004). Boroditsky (2001) also argues that conceptual metaphors can shape thinking about concepts such as time. In an experiment, she demonstrated that Mandarin speakers are more inclined to think of time vertically than English speakers who perceive of time horizontally. Müller (2008) goes further in her research to argue that metaphors are modality independent and are a product of cognitive processes such as attention. Metaphors are also dynamic and are shaped via foregrounding in that the activation of metaphors may be low or high according to the context.

There is a myriad of research investigating conceptual metaphors in English and other languages from different perspectives. However, academic research dedicated to studying conceptual metaphors in Tachelhit is very scarce and almost non-existent. Among the very few studies that tackle metaphor in Tamazight in general and Tachelhit in particular are Mohamed Yeou (2016) and Mohamed Seguenfle (2011), respectively. Nonetheless, the former study deals with semantic extensions of body-parts metaphors only while the latter investigates metaphor semantically in its poetic and linguistic essence more than in its cognitive nature. Also, studies on metaphoric gestures in Tachelhit are non-existent and this research paper serves as a reference and starting point for further studies in this field.

\section{Methodology}

This research paper utilizes a content analysis technique for data collection and analysis. Content analysis, according to Tavakoli (2012), is "a procedure which is used to convert written or spoken information into data that can be analyzed and interpreted (p.101)." The data for this research is taken from the following Tachelhit movies:

Boutfunast Da Hmad (Da Hmad and His Cow), 1992. ${ }^{9}$

Lhokouma (The Government), 2018.

Ajafrrar, 2019. ${ }^{10}$

Kamchich , 2019.

Sidi Mansor, 2019.

Imiss, 2019.

Tirrougza Itmghart (The Power of Women), 2017.

Bizan (Flies Lover), 2017.

Arab World English Journal for Translation \& Literary Studies 
The data taken from these movies through meticulous observation will be translated into English in the Discussion Section of this paper. Communicative translations are given in parentheses once direct translations do not communicate the underlying meaning. However, it is worthy to note that word-for-word translation may be needed by non-Tachelhit speakers to wholly grasp and understand the metaphorical mappings that take place within those conceptual metaphors.

Content analysis as a research technique is advantageous in that it is "unobtrusive." That is, the observer is not observed, and hence the data collected for analysis is not influenced by the presence of the observing researcher. Another major advantage of content analysis according to Tavakoli (2012) is that the researcher is not restricted by time and space; which enables the researcher to access the recorded information of an earlier time. Despite these advantages, content analysis as a technique is disadvantageous in that, as aforementioned, the researcher is restricted to access recorded information only. To avert from this detriment, data is also collected from the mental lexicon of the author of this paper and other native speakers of Tachelhit language through observation. The researcher observed various groups by taking the role of a complete participant.

Research by Jalal Raii (2009) from Tishreen University, who adopted a conceptual approach to examine metaphor in day-to-day Arabic speech, has also been of great use. Few conceptual metaphors which exit ${ }^{11}$ both in Arabic and Tachelhit have been taken, categorized, and further analyzed.

\section{Discussion}

The following conceptual metaphors which to be discussed below cover diverse everyday concepts such as speech, ideas, time, problems and difficulties, weakness, goodness, emotional states and organs, argument, sight, and mind. It is worthy to note, as mentioned before, that the translation will be literal so that the non-Amazigh readers can wholly grasp and understand the metaphorical mappings that take place within those conceptual metaphors. Understanding these mappings is enough to deduce the communicative meaning of the metaphoric linguistic expressions below. However, communicative meaning and additional commentaries will be given- between parentheses- when necessary.

Conceptual metaphors will be presented here from the most productive concepts in Amazigh culture to the least productive ones. The most productive concepts may be taken to be the 'most' important in the Amazigh culture. The following are conceptual metaphors from Tachelhit language which revolve around the concept of time:

\section{TIME IS MONEY/ COMMODITY}

Time here is conceptually structured in terms of a precious substance or commodity (money) which can be given, saved, spent wisely, or wasted. 
AWEJ for Translation \& Literary Studies Volume, 4 Number 2 May 2020

A Conceptual Study of Metaphors in Moroccan Tachelhit Variety

Boussaid

Table 1. TIME IS MONEY/ COMMODITY

\begin{tabular}{|c|c|}
\hline Tachelhit & English Translation \\
\hline Manik asatzrayt luqt? & How do you spend time? \\
\hline Artsxsart luqt. & You squander time. \\
\hline Ijla luqt. & He lost time. \\
\hline Dars 30 cam. & He has thirty years. \\
\hline Ifas rbi tudrt. & God gave him life. \\
\hline
\end{tabular}

\section{TIME IS A HUMAN BEING}

Time, as these metaphoric linguistic expressions reveal, is conceived of as a human being. The following ontological metaphors are also personifications:

Table 2. TIME IS A HUMAN BEING

\begin{tabular}{|c|c|}
\hline Tachelhit & English Translation \\
\hline Argis tșa luqt. & Time is laughing at him. \\
\hline Itabean d luqt. & He is tolerating time. \\
\hline Imay d luqt. & He is fighting with time. \\
\hline
\end{tabular}

\section{TIME IS A MOVING OBJECT}

Time, an abstract concept that we live by, is experienced here as a moving object. The following examples show that the speaker is static; while time is moving towards and passing by the speaker: Table 3. TIME IS A MOVING OBJECT

\begin{tabular}{|c|c|}
\hline Tachelhit & English Translation \\
\hline lkmn lewashir. & The (religious) celebration has arrived. \\
\hline Iqrbd rmdan & Ramadan is approaching. \\
\hline Tushkad luqt lmacqul. & The time of seriousness has come. \\
\hline Artfaray luqt/ artaylal luqt. & Time flies. \\
\hline
\end{tabular}

Arab World English Journal for Translation \& Literary Studies 
AWEJ for Translation \& Literary Studies Volume, 4 Number 2 May 2020

A Conceptual Study of Metaphors in Moroccan Tachelhit Variety

Boussaid

\begin{tabular}{|c|c|}
\hline Tbid luqt. & Time stopped. \\
\hline Izri yanayr dyiya. & January passed fast. \\
\hline Tqrbd leutla & Holiday is approaching. \\
\hline Leam dyushkan. & The upcoming year. \\
\hline Tzri flas lu9t. & Time has passed him. \\
\hline Rak sul tlkm luqt. & Time will reach you. \\
\hline
\end{tabular}

\section{TIME IS A LOCATION}

This conceptual metaphor, on the contrary, is understood as stationary. These metaphoric expressions indicate that time is a location we conceptually head toward to:

Table 4. TIME IS A LOCATION

\begin{tabular}{|c|c|}
\hline Tachelhit & English Translation \\
\hline Artlih s lmustaqbal inu. & I am searching for my future. \\
\hline Ilkm 100 cam. & He reached 100 years. \\
\hline Arnt9rab leid. & We are approaching the (religious) holiday. \\
\hline Nqrb Rmdan. & We are getting near to Ramadan. \\
\hline Ixsak ataqrat bach atuslt. & $\begin{array}{c}\text { You have to study so you can arrive (great } \\
\text { future) }\end{array}$ \\
\hline Iqrb i tmanin cam. & He reached 80 years. \\
\hline Izri xmsin cam. & He stepped over forty. \\
\hline Lhd n lemr ns ayan. & Pass life (enjoy life). \\
\hline Zri tudrt. &
\end{tabular}

These conceptual metaphors are existent in other languages such as English. However, there are few metaphoric linguistic expressions which would sound peculiar if calqued into and used in English. For example: Pass life, time stopped, time laughs at him, and fight with time. The succeeding conceptual metaphors deal with another aspect of human life; that of speech.

Arab World English Journal for Translation \& Literary Studies 


\section{SPEECH IS A COMMODITY/ OBJECT}

Speech is cognitively taken in and constructed in terms of the more concrete source: commodity or object. Speech can go down to the ground to indicate worthlessness, be weighed or empty to suggest value and insignificance, respectively. Speech and words can also be organized, delivered, be moved, and taken away the way we handle concrete objects. The following instances attest to this:

Table 5. SPEECH IS A COMMODITY/ OBJECT

\begin{tabular}{|c|c|}
\hline Tachelhit & English Translation \\
\hline Ika wawal ns akal. & $\begin{array}{l}\text { His speech came down on the ground } \\
\text { (His speech is worthless). }\end{array}$ \\
\hline yayad ika sul yar rg. & This (speech) is scattered all over the ground. \\
\hline Qs-han iwaliwn ns. & His words are hard (he is intolerantly harsh). \\
\hline Iyatinit kra, tuznt. & If you want to say something, weigh it. \\
\hline Urtswa tjmact ns yat. & His speech has no value. \\
\hline Urtsker tjmact ns yat. & His speech is inoperative. \\
\hline Txwa tjmact ns. & His speech is empty. \\
\hline Sgada awal nk. & Organize your speech. \\
\hline Slkm laxbar. & Deliver news. \\
\hline Ks ina $y$ imink. & $\begin{array}{c}\text { Take away my mother from your mouth (do } \\
\text { not talk about my mom). }\end{array}$ \\
\hline Tfay agayunu. & It got out from my head (I forgot it). \\
\hline Tajmazt an tkshim d umzuya tfay d waya. & $\begin{array}{l}\text { Those words got into this ear and got out } \\
\text { from the other ear (not important to heed). }\end{array}$ \\
\hline Tgami atkshim lhdrayan aqalanu. & Her words couldn't get into my head. \\
\hline Manid sim tka tjmast? & $\begin{array}{l}\text { From where did words come from? (Got } \\
\text { news from where?) }\end{array}$ \\
\hline
\end{tabular}

Arab World English Journal for Translation \& Literary Studies 


\section{SPEECH IS FOOD}

Speech is conceptually organized as a whole in terms of food. Speech can be delicious, sweet, or bitter. These conceptual metaphors also show that speech is honey; speech can be swallowed, and taken away:

Table 6. SPEECH IS FOOD

\begin{tabular}{|c|c|}
\hline Tachelhit & English Translation \\
\hline Imim wawal nm. & Your speech is delicious. \\
\hline Uritzri tjmast ns. & His speech can not be swallowed. \\
\hline Tga tjmact ns tamnt. & His words are honey. \\
\hline Tamnt aytfayn $\mathrm{d}$ imins. & Honey is coming out of your mouth. \\
\hline Thara tjmayt ns. & His words are bitter. \\
\hline Ks tajmactan $\gamma$ imink. & $\begin{array}{l}\text { Take away those words from your mouth } \\
\text { (don't talk about it). }\end{array}$ \\
\hline
\end{tabular}

\section{WORDS ARE DELICATE OBJECTS}

Apart from being metaphorically conceived of as a hard object and as food, speech, or words, is also conceptually understood and used as if it were a delicate object:

Table 7. WORDS ARE DELICATE OBJECTS

\begin{tabular}{|c|c|c|}
\hline Tachelhit & English Translation \\
\hline Ardur trzat ri. & $\begin{array}{c}\text { Don't break the words (don't } \\
\text { disagreeably argue }) .\end{array}$ \\
\hline Arisxsar tajmact. & $\begin{array}{c}\text { He is messing up words }(\text { his } \\
\text { words are unpleasant }) .\end{array}$ \\
\hline
\end{tabular}

\section{ARGUMENT IS WAR}

Argument is metaphorically structured in terms of war or fight. When arguing, people can conceptually explode things, kill, block, corner, knead, press, and squeeze other people. We can also break other people's heads when we use words that have weapon-like effect as seen in irza agayunu s tjmaat (He broke my head with words). 
AWEJ for Translation \& Literary Studies Volume, 4 Number 2 May 2020

A Conceptual Study of Metaphors in Moroccan Tachelhit Variety

Boussaid

Table 8. ARGUMENT IS WAR

\begin{tabular}{|c|c|}
\hline Tachelhit & English Translation \\
\hline Sfayd iwaln nk. & $\begin{array}{l}\text { Pop up your eyes (ready-for-fight facial } \\
\text { expression). }\end{array}$ \\
\hline Ersh. & Pose upright. \\
\hline Irza agayunu s tjmaat. & $\begin{array}{l}\text { He broke my head with words (he is } \\
\text { disturbing). }\end{array}$ \\
\hline Sbaqi tarmant. & $\begin{array}{l}\text { Explode the pomegranate (say bad things } \\
\text { and start a fight). }\end{array}$ \\
\hline Sgada awal nk. & Arrange your words. \\
\hline Inyat. & He killed him. \\
\hline Yudas s wakal. & He pressed him to the ground. \\
\hline Imryt y wakal. & He put him to the ground. \\
\hline Iqnk in. & He blocked you. \\
\hline Ihnglatin. & He cornered him. \\
\hline Islsayas ljam. & he reined him \\
\hline Yumzk. & He caught you. \\
\hline Izjnk. & He kneaded you. \\
\hline Igak. & He washed you. ${ }^{12}$ \\
\hline Iesrk. & He squeezed you. \\
\hline Ratsgadah d wakal. & I will flatten him with the ground. \\
\hline Isker gik shifun. & He made you a dirty mat. \\
\hline
\end{tabular}

\section{NEWS IS A HUMAN BEING}

Speech, in the form of news, is, as these metaphoric linguistic expressions display, conceived of as a human being who can be ill or healthy depending if the news are bad or good: 
AWEJ for Translation \& Literary Studies Volume, 4 Number 2 May 2020

A Conceptual Study of Metaphors in Moroccan Tachelhit Variety

Boussaid

Table 9. NEWS IS A HUMAN BEING

\begin{tabular}{|c|c|}
\hline Tachelhit & English Translation \\
\hline Laxbar hrshnin. & Ill news (bad news). \\
\hline Laxbar yuki lhal. & Healthy news (good news). \\
\hline
\end{tabular}

\section{DIRECTNESS IS UP}

Directness in Tachelhit is conceived of vertically. The examples below, which can both translated into 'be direct in your speech', show that being direct is up. This conceptual metaphor also suggests that speech goes vertically from indirectness to directness at the top:

Table 10. DIRECTNESS IS UP

\begin{tabular}{|c|c|}
\hline Tachelhit & English Translation \\
\hline Ut awal y ufla. & Hit the speech from the top. \\
\hline Afla n wawal. & The peak of the speech. \\
\hline
\end{tabular}

\section{WORDS ARE LIQUID}

Words, in this metaphoric expression, are conceptually structured in terms of a liquid. Words flow from one's mouth like a liquid. If the words are unpleasant, the hearer may metaphorically wish that the liquid freezes to obstruct the flow words:

Table 11. WORDS ARE LIQUID

\begin{tabular}{|c|c|}
\hline Tachelhit & English Translation \\
\hline Aniqar y imink. & $\begin{array}{c}\text { May it (words) freeze in your mouth. (Perish } \\
\text { the thought). }\end{array}$ \\
\hline
\end{tabular}

Speech is such a productive concept in Tachelhit. Speech is structured conceptually as if it were a commodity, hard and delicate object, and food. Speech, or words, is also conceived of as a liquid that can freeze to block the flow of bad words from the mouth. Besides, speech in the form of news is personified as a human being who can be healthy or sick (i.e. good or bad news). Argument and directness are structured in terms of war and verticality, respectively. The next conceptual metaphors have to do with problems and difficulties.

Arab World English Journal for Translation \& Literary Studies 


\section{PROBLEMS ARE KNOTS}

Problems are experienced in terms of knots. The solution is resolved once the knot is untied. A problem can also be conceived of- as the third metaphoric linguistic expression attests- as if two people are tied together. They can solve the issue if they know how to disentangle the knot fastening them together:

Table 12. PROBLEMS ARE KNOTS

\begin{tabular}{|c|c|}
\hline Tachelhit & English Translation \\
\hline Tnfasay tmukrist. & The knot has been disentangled. \\
\hline Tfuka tmukrist. & The knot has been unknotted. \\
\hline Ursnh manik asadik nfuku. & $\begin{array}{l}\text { I don't know how to disentangle from you (I } \\
\text { don't know how to solve the issue with you). }\end{array}$ \\
\hline Ifukat. & He unknotted it. \\
\hline Maygan amukris nk? & What is your knot? (What is your problem?) \\
\hline
\end{tabular}

\section{DIFFICULTIES ARE IMPEDIMENTS TO MOTION}

Aside from being conceptually structured as knots, problems, or difficulties, are metaphorically understood as impediments to motion. As the table below shows, difficulties can be carried, burden you, or be lifted as heavy objects:

Table 13. DIFFICULTIES ARE IMPEDIMENTS TO MOTION

\begin{tabular}{|c|c|}
\hline Tachelhit & English Translation \\
\hline Yusi lhm. & He is carrying worry. \\
\hline Tzday flas tmukrist an. & That problem burdened him. \\
\hline Tusit yili ytzday. & $\begin{array}{c}\text { He lifted it (the problem) from the heavy } \\
\text { side. }\end{array}$ \\
\hline
\end{tabular}

\section{PROBLEMS ARE LOCATIONS}

Problems are not just knots or impediments, but also locations. A person can be in a problem, get struck in a problem, or keep away from a problem: 
AWEJ for Translation \& Literary Studies Volume, 4 Number 2 May 2020

A Conceptual Study of Metaphors in Moroccan Tachelhit Variety

Boussaid

Table 14. PROBLEMS ARE LOCATIONS

\begin{tabular}{|c|c|}
\hline Tachelhit & English Translation \\
\hline Ila $\gamma$ tmukrist. & He is in a problem. \\
\hline Ituz y tmukrist an. & He got stuck in that problem. \\
\hline Itin y tmukrist an. & Keep away from that problem. \\
\hline
\end{tabular}

The following conceptual metaphors deal with various concepts which have to do with emotional states, seeing, ideas, hunger, sleeping, goodness, stupidity, repute, usefulness, weakness, money, mind, and quantity:

\section{EMOTIONAL STATES ARE ORGANS AND (BRITTLE) OBJECTS}

In Tamazight culture, the liver is seen as the location of emotions. ${ }^{13}$ In Euro-American culture, however, the heart is perceived as the site of emotions. The liver can be cut, burnt, exploded, and broken to convey the meaning of being extremely sad. Hearts can also be dead to express the meaning of being indifferent to something. Moreover, emotional states are also conceptually structured as fragile objects that can be disorganized, collapsed, lost, crashed (like a system crash), or entangled. The following examples confirm to this:

Table 15. EMOTIONAL STATES ARE ORGANS AND OBJECTS

\begin{tabular}{|c|c|}
\hline Tachelhit & English Translation \\
\hline Tbi tasanu. & My liver is cut (I am sad). \\
\hline Tjder tasanu & My liver is burnt (I am sad/ suffering). \\
\hline Imut ul ns. & His heart is dead (He is indifferent/ careless). \\
\hline Tsxsrt lxater inu. & $\begin{array}{c}\text { You disorganized my mood (you made me } \\
\text { made }\end{array}$ \\
\hline Ixla. & He is collapsed (He is crazy). \\
\hline Ifayt leaqlns. & His mind got out. \\
\hline Idayas leaql ns. & I don't have mind. \\
\hline Urtafy leaql. & He broke my liver (Heartbroken). \\
\hline Irza tasanu & \\
\hline
\end{tabular}

Arab World English Journal for Translation \& Literary Studies 
AWEJ for Translation \& Literary Studies Volume, 4 Number 2 May 2020

A Conceptual Study of Metaphors in Moroccan Tachelhit Variety

Boussaid

\begin{tabular}{|c|c|}
\hline Isbaqi tasanu & He exploded my liver (He broke my heart). \\
\hline Ixla f tfruxt an & $\begin{array}{c}\text { He collapsed over her (He is so mad about } \\
\text { her). }\end{array}$ \\
\hline Ișuṭi ywana. & He crashed (He is crazy). \\
\hline Nhabarn ifalan ns. & His strings are entangled (He is crazy). \\
\hline
\end{tabular}

\section{SEEING IS TOUCHING and EYES ARE LIMBS}

Seeing is touching. To see someone or to glare at him is to put or stuck eyes on him. Seeing is also conceived of like a mouth that can eat someone or be quenched with water. Eyes are also conceptually understood as limbs that can hit and reach people ${ }^{14}$ :

Table 16. SEEING IS TOUCHING and EYES ARE LIMBS

\begin{tabular}{|c|c|}
\hline Tachelhit & English Translation \\
\hline Istuz giti iwaln ns. & He stuck his eyes on me. \\
\hline Igami agiti yal iwaln ns. & He could not lift his eyes off me. \\
\hline Tut tiṭ. & He ate me wit him. \\
\hline Ishayi s iwaln ns. & He put his eyes on me. \\
\hline Isrs flati iwaln ns. & $\begin{array}{r}\text { You won't see them nor will you have them } \\
\text { quench the thirst of your eyes. }\end{array}$ \\
\hline Uratn tzrt ola tswit gisn izrinm. & Eyes can reach her. \\
\hline Hkamt waln. &
\end{tabular}

\section{SEEING IS LIGHT/ UNDERSTANDING}

To see light is to understand, to see darkness is to not understand something. Seeing darkness can also mean being blind:

Table 17. SEEING IS LIGHT/ UNDERSTANDING

\begin{tabular}{|c|c|}
\hline Tachelhit & English Translation \\
\hline Urisfaw agayuns. & He can not see himself. \\
\hline
\end{tabular}

Arab World English Journal for Translation \& Literary Studies 
AWEJ for Translation \& Literary Studies Volume, 4 Number 2 May 2020

A Conceptual Study of Metaphors in Moroccan Tachelhit Variety

Boussaid

\begin{tabular}{|c|c|}
\hline Isak tbayn kran tifawt? & Can you see some light? \\
\hline Urtsfawt. & You are blind. \\
\hline Uryina tsfawt walu. & You can not see anything. \\
\hline Tilas ayitbayan. & I can only see darkness. \\
\hline Urak ibayn yat? & Is anything clear to you? \\
\hline
\end{tabular}

\section{IDEAS ARE HUMAN BEINGS}

This ontological metaphor is conceptually understood in a human-like quality, i.e. being able to pay visits:

Table 18. IDEAS ARE HUMAN BEINGS

\begin{tabular}{|c|c|}
\hline Tachelhit & English Translation \\
\hline Xta urju tka agayunu. & This (idea) has never visited my head. \\
\hline
\end{tabular}

\section{IDEAS ARE OBJECTS}

This conceptual metaphor shows that ideas are structured in terms of concrete objects that can revolve, be in the head, get out of the head, or be seen:

Table 19. IDEAS ARE OBJECTS

\begin{tabular}{|c|c|}
\hline Tachelhit & English Translation \\
\hline Agayumn uragis itdwar umya. & Nothing (ideas) revolves in your head. \\
\hline Maylan y ugayunk? & What is in your head? \\
\hline Tfay agayunu. & (The idea) got out of my head. \\
\hline Xtad urtin anih. & I did not see this one (idea). \\
\hline
\end{tabular}

\section{HUNGER IS A KILLING THING}

Hunger can be a displeasing thing. However, it is metaphorically experienced in Tachelhit as a killing thing; a person or a disease:

Table 20. HUNGER IS A KILLING THING

\begin{tabular}{|c|c|}
\hline Tachelhit & English Translation \\
\hline Inyayi laz. & Hunger killed me (I am hungry). \\
\hline
\end{tabular}

Arab World English Journal for Translation \& Literary Studies 
AWEJ for Translation \& Literary Studies Volume, 4 Number 2 May 2020

A Conceptual Study of Metaphors in Moroccan Tachelhit Variety

Boussaid

Imut s jue.

He died because of hunger (He is starving).

\section{SLEEPING IS UNAWARENESS}

A sleeper is metaphorically seen as being unconscious or in a deep well:

Table 21. SLEEPING IS UNAWARENESS

\begin{tabular}{|c|c|}
\hline Tachelhit & English Translation \\
\hline Urta dicaql? & Is he still unconscious? \\
\hline Iginn $\gamma$ wanu. & He slept in a deep well (deep sleep). \\
\hline
\end{tabular}

\section{USEFULNESS IS A PRECIOUS OBJECT}

Usefulness conceived of as a precious thing that can be located, owned, or taken:

Table 22. USEFULNESS IS A PRECIOUS OBJECT

\begin{tabular}{|c|c|}
\hline Tachelhit & English Translation \\
\hline urgis lfayt & Usefulness is not in him (He is useless). \\
\hline Urṭaf lfayt & You don't have usefulness. \\
\hline Ksn gis lfayt. & $\begin{array}{c}\text { They took usefulness from him (seen as } \\
\text { useless). }\end{array}$ \\
\hline
\end{tabular}

\section{REPUTE IS A DELICATE OBJECT}

Repute is something that needs to be wholeheartedly regarded; otherwise, someone will conceptually break it, as the following example displays:

Table 23. REPUTE IS A DELICATE OBJECT

\begin{tabular}{|c|c|}
\hline Tachelhit & English Translation \\
\hline Trza learada nu. & She broke (did harm to) my repute. \\
\hline
\end{tabular}

\section{WEAKNESS IS EMPTINESS}

Empty knees are weak ones. The reverse is correct. Knees are also conceptualized as containers that need to be filled to have energy and strength: 
AWEJ for Translation \& Literary Studies Volume, 4 Number 2 May 2020

A Conceptual Study of Metaphors in Moroccan Tachelhit Variety

Boussaid

Table 24. WEAKNESS IS EMPTINESS

\begin{tabular}{|c|c|}
\hline Tachelhit & English Translation \\
\hline Xwan ifadn. & The knees are empty (weak). \\
\hline
\end{tabular}

GOODNESS IS A STRAIGHT LINE ${ }^{15}$

Goodness is metaphorically conceptualized as a straight path. A good person is on the path, while a bad person is off the path. A good person can also have a good path, while a bad person can have a bad path:

Table 25. GOODNESS IS A STRAIGHT LINE

\begin{tabular}{|c|c|}
\hline Tachelhit & English Translation \\
\hline Ifay ayaras. & He went astray from the path. \\
\hline Tayarast ns txshin. & His path is bad. \\
\hline
\end{tabular}

\section{STUPIDITY IS A DONKEY}

A donkey is associated with stupidity in many languages. However, a tricked or a foolhardy person is also referred to as a donkey. A person can put a donkey saddle on you (trick you, make you stupid), or make a donkey from you (make you stupid):

Table 26. STUPIDITY IS A DONKEY

\begin{tabular}{|c|c|}
\hline Tachelhit & English Translation \\
\hline Islsayas ahlays. & $\begin{array}{c}\text { He put the donkey saddle on him (He made } \\
\text { him stupid). }\end{array}$ \\
\hline Isker gis ayyul. & He made him a donkey. \\
\hline
\end{tabular}

\section{MONEY IS DIRT ${ }^{16}$}

Money is metaphorically talked about as filth. A person can stink with money because he has filth (riches). This does not refer to dirty money earned illegally. Illegal money is lflus $n$ lhram $\mathrm{n}$ Tachelhit:

Table 27. MONEY IS DIRT

\begin{tabular}{|c|c|}
\hline Tachelhit & English Translation \\
\hline Ijja s lflus. & He stinks with money (he is rich $).$ \\
\hline
\end{tabular}

Arab World English Journal for Translation \& Literary Studies 
AWEJ for Translation \& Literary Studies Volume, 4 Number 2 May 2020

A Conceptual Study of Metaphors in Moroccan Tachelhit Variety

Boussaid

Irkan n dunit.

The filth of the earth.

\section{QUANTITY IS VERTICALITY}

Anger and price are both conceptually structured in terms of verticality. As you add more quantity, things go up. As blood goes up, the angrier you are. The more costly things are, the higher they go; the cheaper they are, the lower they go:

Table 28. QUANTITY IS VERTICALITY

\begin{tabular}{|l|c|}
\hline Tachelhit & English Translation \\
\hline yliniyi idamn. & My blood rose (I am angry). \\
\hline Iyli watig ns. & Its price went up. \\
\hline Idr watig ns. & Its price went down. \\
\hline
\end{tabular}

\section{MIND IS A BRITTLE OBJECT}

Mind, the generator of all these metaphors, is metaphorically constructed as a brittle object. This object can be a fragile and delicate feather, a device that can crash, or a frame that can break down: Table 29. MIND IS A BRITTLE OBJECT

\begin{tabular}{|c|c|}
\hline Tachelhit & English Translation \\
\hline Lah tarisht n leaql. & His mind is fragile as a feather (He is insane). \\
\hline Ișuṭi. & He crashed. \\
\hline Ixla. & He broke down. \\
\hline
\end{tabular}

Conceptual metaphors do not only structure linguistic expressions, but also gestures.

\section{Metaphoricity in Gesture}

Gestures, if observed with a meticulous eye, can show that they are well structured and organized according to conceptual metaphors. Some of these gestural metaphors can be universal in the sense that it is a bodily phenomenon which all people experience. For example, for most communities, people see the future as being ahead and past as being behind. This conceptual metaphor, FUTURE IS FORWARD/ PAST IS BACKWARD, can be observed in our gestures when we put our hands outward and backwards to refer to future and past, respectively. In some cultures, the reverse could be true.

Another example is how social status, increase in prices, and events are metaphorically structured in our gestures. When talking about social status or increase in prices, our hands tend to go up vertically. Contrariwise, our hands move horizontally from right to left or from left to right

Arab World English Journal for Translation \& Literary Studies 
when we converse about events in time. Also, people can also metaphorically conceive of ideas as objects. The conceptual metaphor IDEAS ARE OBJECTS can be observed in gestures when people put forward their bowl-shaped hands as if holding an object which represents the idea they are talking about. The speaker, if agreed to the idea, will pull the hand towards his chest. If the idea is rejected, he will exhibit with his hand that he is putting or throwing that idea away.

However, other gestural metaphors may be differently conceived or interpreted due to the cultural contexts in which languages take place. The following are some of the metaphoric gestures which have been observed:

A speaker of Tachelhit can present a hand with the palm facing up as if holding an object which stands for the idea. The hand would then move slightly up and down as if weighing that unseen object which metaphorically stands for the idea. If the metaphoric gesture suggests that the object is heavy, then the idea is important. On the contrary, if the gesture shows that the object is light, then the idea is trivial. The conceptual metaphor that structures this gesture is: HEAVINESS IS IMPORTANCE (figure one).

When speaking about a goal to be achieved, a speaker's gestures may unconsciously be structured in terms of an ascent: PERSEVERANCE IS AN ASCENT (figure two). The speaker would show a hand that goes up step by step as if ascending a ladder or stairs. Another conceptually metaphoric gesture is when people interlock their fingers together forming a knot to metaphorically refer to a problem PROBLEMS ARE KNOTS (figure three).

Among Tachelhit speakers, it is also noticed that a person would protrude his straight index fingers from their formed fists and then adjoin their index finger together to metaphorically communicate rapport and friendship: RAPPORT IS PHYSICAL CLOSENESS (figure four). On the contrary, a person conveys animosity by protruding his crooked index fingers from his fists while hooking them together to signal tightness: ANIMOSITY IS PHYSICAL TIGHTNESS (figure five).

Metaphoricity in gesture is also depicted when people talk about fineness or excellence. A person would refer to excellence by making a squeezed fist with the thumb squeezed against the index finger. The conceptual metaphor in effect here is: EXCELLENCE IS FIRMNESS (figure 6).

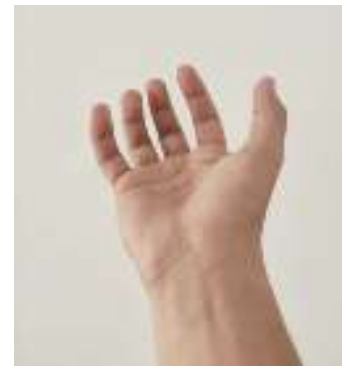

Figure 1. HEAVINESS IS IMPORTANCE

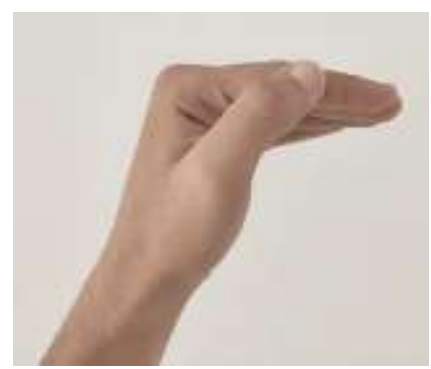

Figure 2. PERSERVERANCE IS AN ASCENT

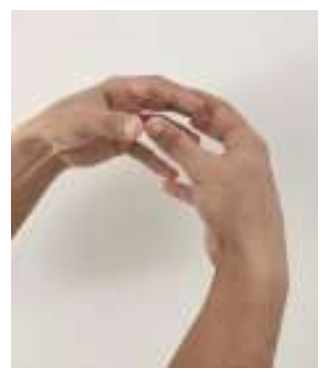

Figure 3. PROBLEMS ARE KNOTS

Arab World English Journal for Translation \& Literary Studies ISSN: 2550-1542 | www.awej-tls.org 


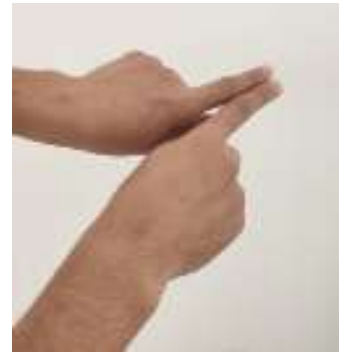

Figure 4. RAPPORT IS PHYSICAL CLOSENESS

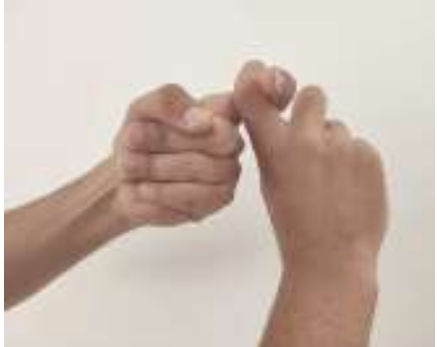

Figure 5. ANIMOSITY IS PHYSICAL TIGHTNESS

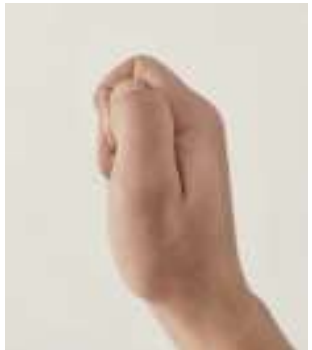

Figure 6. EXCELLENCE

IS FIRMNESS

It is very important to note that metaphoric gestures may be subject to different interpretations within different communities as well as in different contexts. Intertwining fingers, for instance, may refer to a problem or teamwork.

The analysis of the conceptual metaphors in Tachelhit shows that Tachelhit and English do share certain conceptual metaphors related to time, emotions, speech, argument, problems, sight, ideas, sleeping, quantity and mind. These conceptual metaphors are, but not limited to: TIME IS MONEY, TIME IS A MOVING OBJECT, TIME IS A LOCATION, SPEECH IS FOOD, ARGUMENT IS WAR, PROBLEMS ARE KNOTS AND LOCATIONS, DIFFICULTIES ARE IMPEDIMENTS TO MOTION, EMOTIONAL STATES ARE ORGANS, SEEING IS TOUCHING, EYES ARE LIMBS, SEEING IS UNDERSTANDING, IDEAS ARE OBJECTS, SLEEPING IS UNAWARENESS, STUPIDITY IS A DONKEY, QUANTITY IS VERTICALITY, MIND IS A BRITTLE OBJECT.

However, the two languages do differ to a higher extent in some other conceptual metaphors related to time, sight, money, goodness, hunger, usefulness, repute, weakness, and speech. These conceptual metaphors include, but are not limited to: TIME IS A HUMAN BEING, NEWS IS A HUMAN BEING, DIRECTNESS IS UP, WORDS ARE LIQUID, HUNGER IS A KILLING THING, WEAKNESS IS EMPTINESS, GOODNESS IS A STRAIGHT LINE, MONEY IS DIRT, USEFULNESS IS A PRECIOUS OBJECT and REPUTE IS A DELICATE OBJECT. These conceptual metaphors are vital elements that need be taken into consideration in intercultural as well as intracultural contexts to overcome communication failures.

The findings of this research are of paramount importance in that they shed light on the cultural groupthink of the Amazigh people in Morocco. The research is also essential in that it presents its findings as a starting point for further research aiming at contributing to the field of metaphor in Tamazight linguistics as well as filling the gap that exists in its literature. Metaphor, as may be considered by many, is not just a poetic ornament, but rather a conceptual phenomenon that is pervasive in our daily language. 


\section{Conclusion}

It is demonstrated through this research paper that metaphor is a conceptual experience that pervades our everyday speech. It is also seen that Tachelhit shares some conceptual metaphors with English but differs in others. For example, Time is a Human Being, News is a Human Being, Directness is Up, Words are Liquid, Seeing is Touching, Eyes are Limbs, Hunger is a Killing Thing, Weakness is Emptiness, Goodness is a Straight Line, and Money is Dirt.

Conceptual metaphors structure gestures as well. These metaphoric gestures are a tool used unconsciously to communicate abstract things. Conceptual metaphors as depicted by linguistic expressions and gestures are subjected to universality as well as variation. The reasons for variation, as mentioned by Kövecses (2010), are the broader cultural context and the natural and physical environment of a language.

The study of metaphor can shed light on different ways people conceive of things. Knowing the cultural groupthink of a society, on which conceptual metaphors are built, is a key for overcoming intercultural communication barriers and failures caused by unawareness of metaphor variation across languages. Moreover, the study of metaphoric gestures can also reveal the speaker's real focus of attention in real-time communication.

From this point, it is recommended that further research can be done to investigate the linguistic and socio- cultural causes of metaphor variation across and within Moroccan communities. Further research is also needed to examine the multi-metaphoric gestures that speakers display when conversing. This may have vital applications in the fields of cognitive linguistics, communication and discourse studies.

\section{Endnotes}

${ }^{1}$ Tamazight is preferred here as the name of the language under study since the word 'Berber' is derogatory. The diphthong $g h$, in the word Tamazight, is a voiced velar fricative, and can be written and also transcribed as $/ \gamma /$.

${ }^{2}$ It is noteworthy to point out that the word Tamazight refers both to the dialect in the center of Morocco and also to the Berber language in general. Tamazight is also the name of the official language of Morocco.

${ }^{3}$ Cultural models are "best conceived of as any coherent organizations of human experience shared by people.” (Kövecses, 2005, p.193).

${ }^{4}$ ARGUMENT IS WAR is a conceptual metaphor, while the three expressions below it are called metaphorical linguistic expressions.

5 There are other metaphorical concept examples of orientational metaphors. For example: good is up, bad is down/ health and life are up, sickness and death are down. Further examples can be found in Lakoff and Johnson's Metaphors We Live By.

${ }^{6}$ Personification can be considered as a type of ontological metaphor (Kövecses, 2010).

7 The ability to mind read in this context has nothing to do with occult. It merely means that gesticulants can sometimes reveal what the speaker is thinking about.

Arab World English Journal for Translation \& Literary Studies 
${ }^{8}$ These gestures may mean the opposite in other cultures since the conceptual metaphors that structure gestures are different; PAST IS UP/ FUTURE IS DOWN.

${ }^{9}$ This movie's date of publication refers to the date when the movie was officially released in cassettes, while the rest of other movies' dates refer to their publication in YouTube only.

${ }^{10}$ The untranslated titles are just proper nouns.

${ }^{11}$ There are also metaphors which have been calqued (borrowed) from Arabic to Tamazight and vice versa, since these two languages have been in contact for ages, especially in Tamazgha region. These conceptual metaphors can still shed light on the cultural groupthink of both Arab and Amazigh people.

${ }^{12}$ This refers to being washed with force as people used to (or may still) wash clothes. This may involve just hands, a club that hits and squeezes clothes, or a wooden washing board with bumps by which clothes are forcefully pressed against and pulled up and down over the bumps.

${ }^{13}$ Other unrelated languages such as Indonesian language also conceive of liver as the place of emotion: patah hati (heartbroken/ sad).

${ }^{14}$ Eyes as having power that can hit or reach people may have root in magic and superstition in which people believe in.

${ }^{15}$ This conceptual metaphor could be calqued from the Quran.

${ }^{16}$ This conceptual metaphor may persist in the minds of poor people who envy rich people. It is also a characteristic of Sufi people.

\section{About the author:}

Youness Boussaid is a teacher of English language in Awesome Foreign Studies Center in Tianjin, China. He holds a bachelor's degree in English linguistics from Ibn Zohr university. His research interests include pragmatics, metaphor and second language acquisition.

https://orcid.org/0000-0002-6684-6354

\section{References}

Boroditsky, L. (2001). Does Language Shape Thought?: Mandarin and English Speakers' Conceptions of Time. Cognitive Psychology 43, 1-22.

Bussmann, H. (1996). Routledge Dictionary of Language and Linguistics (G. P. Trauth \& K. Kazzazi, Trans.). London: Routledge.

Chaker, S., \& Mettouchi, A. (2006). Berber. In K. Brown, \& S. Ogilvie (Eds.), Concise encyclopedia of languages of the world (pp. 152-157). Oxford: Elsevier Ltd.

Cienki, A. (2008). Why study metaphor and gesture? In A. Cienki, \& C. Müller, Metaphor and gesture (gesture studies V3, pp. 219-245). Amsterdam: John Benjamins Publishing Co.

Kövecses, Z. (2005). Metaphor in culture: universality and variation. Budapest: Eötvös Loránd University

Kövecses, Z. (2010). Metaphor: A practical introduction (2 $2^{\text {nd }}$ ed.). New York: Oxford University Press.

Krishnamurthy, R. (2005). Teaching and learning English metaphors. Japan: JALT 
Lakoff, G. (1992). The contemporary theory of metaphor. In A. Ortony (Ed.), Metaphor and thought ( $2^{\text {nd }}$ ed, pp. 202-251). Cambridge: Cambridge University Press.

Lakoff, G. (2004). Don't think of an elephant: Know your values and frame the debate- The essential guide for progressives. White River Jct., Vt.: Chelsea Green.

Lakoff, G. (2008). The neural theory of metaphor. In R. Gibbs, (ed.), The Cambridge Handbook of Metaphor and Thought (pp. 17-38). Cambridge: Cambridge University Press.

Lakoff, G. (2004). Don't think of an elephant! Know your values and frame the debate: the essential guide for progressives. White River Junction, Vt: Chelsea Green Pub. Co.

Lakoff, G., \& Johnson, N. (1980). Metaphors we live by. Chicago: The university of Chicago press.

McNeil, D. (1992). Hand and Mind: What gestures reveal about thought. Chicago: University of Chicago Press.

Raii, J. (2009). Metaphor in day-to-day Arabic speech: A conceptual approach. Tishreen University Journal for Research and Scientific Studies-Arts and Humanities Series, 31 (1), 175-193.

Seguenfle, M. (2011). La métaphore dans la littérature amazighe [Metaphor in Amazigh literature]. Morocco: Éditions Universitaires Européennes

Tavakoli, H. (2012). A dictionary of research and methodology and statistics in applied linguistics. Iran: Rahnama Press.

Thibodeau, P. H., \& Boroditsky, L. (2011). Metaphors we think with: The role of metaphor in reasoning. PLoS ONE, 6(2), Article e16782.

Yeou, M. (2016). Metaphor and Metonymy in Body Parts in some Amazigh Varieties: The Case of the 'Head' and its Parts. Asinag, 11, 2016, p. 89-113 